\title{
Esophageal submucosa: The watershed for esophageal cancer
}

\author{
Siva Raja, MD, PhD, ${ }^{a}$ Thomas W. Rice, MD, ${ }^{a}$ John R. Goldblum, MD, ${ }^{\mathrm{b}}$ Lisa A. Rybicki, MS, ${ }^{\mathrm{c}}$ \\ Sudish C. Murthy, MD, PhD, ${ }^{\mathrm{a}}$ David P. Mason, MD, ${ }^{\mathrm{a}}$ and Eugene H. Blackstone, $\mathrm{MD}^{\mathrm{a}, \mathrm{c}}$
}

Objectives: Submucosal esophageal cancers (pT1b) are considered superficial, implying good survival. However, some are advanced, metastasizing to regional lymph nodes. Interplay of cancer characteristics and lymphatic anatomy may create a watershed, demarcating low-risk from high-risk cancers. Therefore, we characterized submucosal cancers according to depth of invasion and identified those with high likelihood of lymph node metastases and poor survival.

Methods: From 1983 to 2010, 120 patients underwent esophagectomy for submucosal cancers at Cleveland Clinic. Correlations were sought among cancer characteristics (location, dimensions, histopathologic cell type, histologic grade, and lymphovascular invasion [LVI]), and their associations with lymph node metastasis were identified by logistic regression. Associations with mortality were identified by Cox regression.

Results: As submucosal invasion increased, cancer length $(P<.001)$, width $(P<.001)$, area $(P<.001)$, LVI $(P=.007)$, and grade $(P=.05)$ increased. Invasion of the deep submucosa $(P<.001)$ and LVI $(P=.06)$ predicted lymph node metastases: $45 \%$ (23/51) of deep versus $10 \%(3 / 29)$ of middle-third and $7.5 \%(3 / 40)$ of inner-third cancers had lymph node metastases, as did $46 \%$ (12/26) with LVI versus $18 \%$ (17/94) without. Older age and lymph node metastases predicted worse 5 -year survival: $94 \%$ for younger pN0 patients, $62 \%$ for older pN0 patients, and $36 \%$ for $\mathrm{pN} 1-2$ patients regardless of age.

Conclusions: Submucosal cancer characteristics and lymphatic anatomy create a watershed for regional lymph node metastases in the deep submucosa. This previously unrecognized divide distinguishes superficial submucosal cancers with good survival from deep submucosal cancers with poor survival. Aggressive therapy of more superficial cancers is critical before submucosal invasion occurs. (J Thorac Cardiovasc Surg 2011;142:1403-11)

Supplemental material is available online.

Submucosal esophageal cancers (pT1b) are considered superficial cancers, implying early cancer with good survival. However, some metastasize to regional lymph nodes and behave like advanced cancers. ${ }^{1}$ Recently discovered nonhomogeneous esophageal lymphatic anatomy in the mucosa and submucosa $a^{2,3}$ (Figure 1), coupled with evolving cancer characteristics with growth, ${ }^{4}$ may create a watershed that

\footnotetext{
From the Heart and Vascular Institute, Department of Thoracic and Cardiovascular Surgery, ${ }^{\mathrm{a}}$ the Pathology and Laboratory Medicine Institute, Department of Anatomic Pathology, ${ }^{\mathrm{b}}$ and the Research Institute, Department of Quantitative Health Sciences, ${ }^{\mathrm{c}}$ Cleveland, Ohio.

This study was funded in part by the Daniel and Karen Lee Endowed Chair in Thoracic Surgery (to Dr Rice) and the Kenneth Gee and Paula Shaw, PhD, Chair in Heart Research (to Dr Blackstone).

Disclosures: Authors have nothing to disclose with regard to commercial support.

Read at the 91st Annual Meeting of The American Association for Thoracic Surgery, Philadelphia, Pennsylvania, May 7-11, 2011.

Received for publication April 26, 2011; revisions received Aug 4, 2011; accepted for publication Sept 22, 2011.

Address for reprints: Thomas W. Rice, MD, Cleveland Clinic Department of Thoracic and Cardiovascular Surgery, 9500 Euclid Avenue / Desk J4-1, Cleveland, OH 44195 (E-mail: ricet@ccf.org).

$0022-5223 / \$ 36.00$

Copyright (C) 2011 by The American Association for Thoracic Surgery

doi:10.1016/j.jtcvs.2011.09.027
}

sharply distinguishes submucosal cancers with good survival from those with poor survival. Therefore, we characterized submucosal cancers according to depth of invasion and identified those with high likelihood of lymph node metastases and poor survival.

\section{PATIENTS AND METHODS \\ Patients}

From January 1983 to January 2010, 1296 patients underwent esophagectomy for cancer at Cleveland Clinic. Of these, 120 had a pathologic diagnosis of adenocarcinoma or squamous cell carcinoma invading the submucosa but not beyond (pT1b). All had esophagectomy alone without induction therapy (Table 1). The esophagectomy database used for this study was approved for use in research by the Institutional Review Board of Cleveland Clinic, with patient consent waived.

\section{Cancer Characteristics}

Cancer location and Barrett length were measured at endoscopy. Cancer dimensions were measured from the resection specimen. $\mathrm{cT}$ was determined by endoscopic ultrasound $(n=105)$ and biopsy $(n=15)$. Depth of cancer invasion within the submucosa (pT1b) was classified visually as inner (SM1), middle (SM2), or deep (SM3) thirds. Lymphovascular invasion was histologically identified by invasion of endothelium-lined spaces by cancer. Lymph node status was determined from final pathologic analysis using staging criteria from the seventh edition of the American Joint Committee on Cancer Staging Manual..$^{5}$

\section{End Point and Follow-up}

The end point was all-cause mortality. Cross-sectional systematic follow-up of patients was complete in $115(96 \%)$ and partial in 


\section{Lymphatics}

\section{Anatomic Layers}

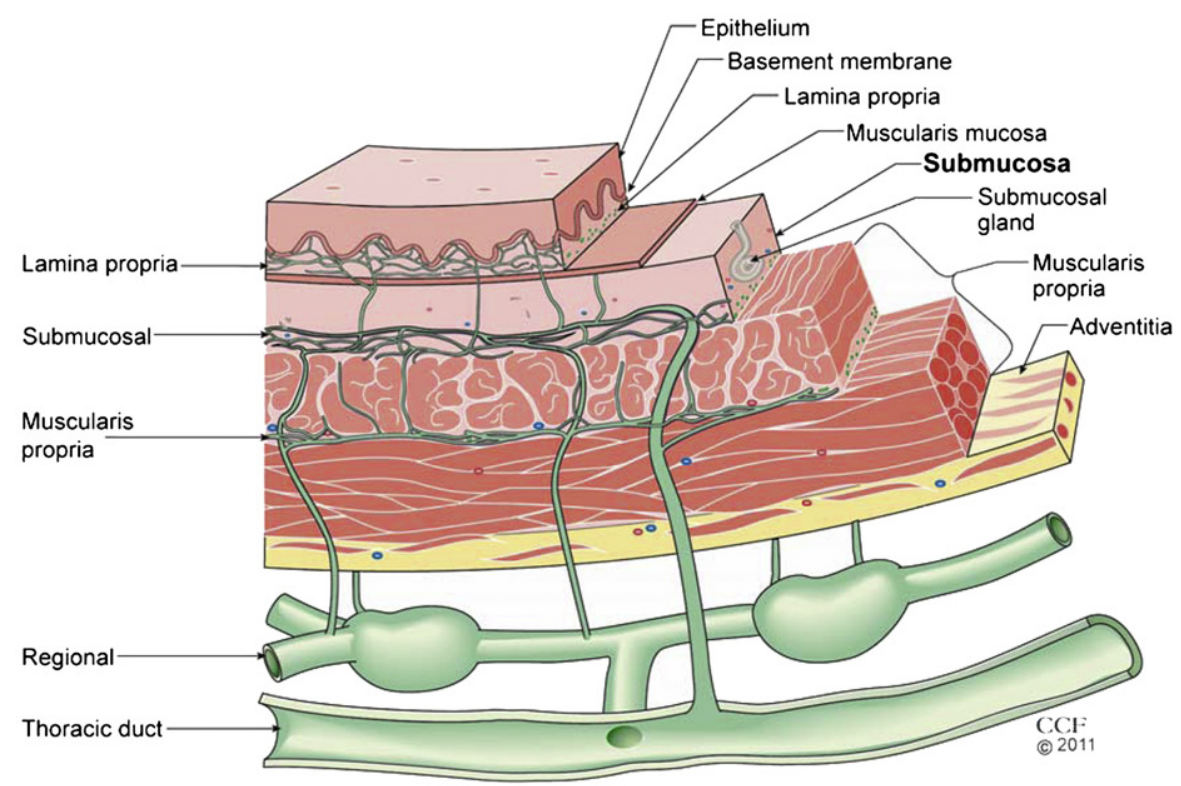

A

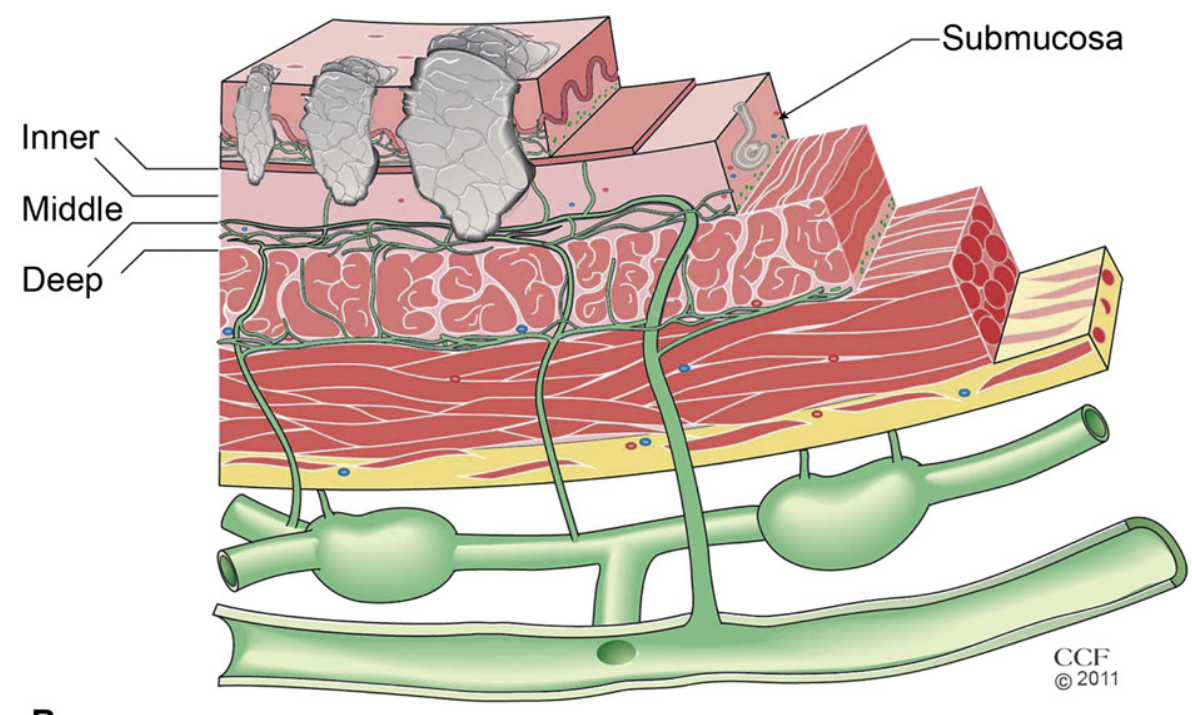

B

FIGURE 1. Cross-section of esophageal wall and lymphatics. A, Normal esophagus demonstrating lymphatic anatomy. B, Cancer invasion into inner, middle, and deep submucosa.

$5(4.2 \%)$. Median follow-up of living patients was 4.4 years; $25 \%$ of survivors were followed up for 8 years and $10 \%$ for more than 11 years.

\section{Submucosal Cancer Characteristics}

Binary variables were compared according to depth of invasion using the Cochran-Armitage test; continuous variables were compared using the Jonckheere-Terpstra test; and ordinal variables were compared using the Cochran-Mantel-Haenszel correlation test.

\section{Lymph Node Metastasis}

Owing to the small number of $\mathrm{pN} 2$ patients, lymph node metastases were analyzed as any $(\mathrm{pN}+)$ versus none $(\mathrm{pN} 0)$. Logistic regression analysis was used to assess association of individual factors with lymph node metastasis (Appendix 1). Results are summarized as univariable odds ratios, $68 \%$ confidence interval for the odds ratios, and corresponding $P$ value. Multivariable analysis used variables listed in Appendix 1 and used bagging for variable selection. ${ }^{6}$ In brief, 1000 bootstrap samples of size 120 were selected with replacement from the study data. Stepwise logistic regression models were obtained for each with an entry criterion of $P \leq$ .10 and retention criterion of $P \leq .05$. The percentage of times each factor appeared in a stepwise model was tabulated. Variables appearing in more than $50 \%$ of models were considered reliable. Separate analysis was made of specific interactions of cancer size (depth, length, width, and area) with lymph node metastasis. 
TABLE 1. Patient, cancer, and treatment characteristics

\begin{tabular}{|c|c|}
\hline Characteristic & No. of patients $(\%)$ \\
\hline \multicolumn{2}{|l|}{ Demographics } \\
\hline Men & $102(85)$ \\
\hline \multicolumn{2}{|l|}{ Race } \\
\hline White & $116(97)$ \\
\hline African American & $3(2.5)$ \\
\hline Other & $1(0.8)$ \\
\hline Age at operation $(y)$, mean \pm SD & $64 \pm 10$ \\
\hline \multicolumn{2}{|l|}{ Cancer characteristics } \\
\hline \multicolumn{2}{|l|}{ Location } \\
\hline Upper esophagus & $1(0.8)$ \\
\hline Middle esophagus & $5(4.2)$ \\
\hline Lower esophagus & $114(95)$ \\
\hline Barrett length $(\mathrm{cm})$ & $0 / 3 / 9 *$ \\
\hline \multicolumn{2}{|l|}{$\mathrm{cT}$} \\
\hline cTx & $15(12)$ \\
\hline cTis & $5(4.2)$ \\
\hline cT1 & $50(42)$ \\
\hline cT2 & $38(32)$ \\
\hline cT3 & $11(9.2)$ \\
\hline cT4 & $1(0.8)$ \\
\hline \multicolumn{2}{|l|}{ pT1b } \\
\hline Inner & $40(33)$ \\
\hline Middle & $29(24)$ \\
\hline Deep & $51(42)$ \\
\hline \multicolumn{2}{|l|}{ Esophagectomy } \\
\hline Transhiatal & $46(38)$ \\
\hline Thoracotomy & $74(62)$ \\
\hline
\end{tabular}

$S D$, Standard deviation. *The 15 th, 50 th, and 85 th percentiles.

\section{Survival}

Nonparametric survival estimates were obtained using the KaplanMeier method. Stratified estimates were compared with the log-rank test. Cox proportional hazards regression was used to assess individual associations with survival. Results are summarized as univariable hazard ratios, $68 \%$ confidence interval for the hazard ratios, and $P$ values. Multivariable analysis used variables in Appendix 1 plus number of nodes resected and $\mathrm{pN} 0$ versus $\mathrm{pN}+$ for variable selection as described previously. Exploratory recursive partitioning analysis was used to illustrate the relation of age and lymph node metastasis to survival. ${ }^{7}$

\section{Presentation}

Continuous variables are summarized as mean \pm 1 standard deviation for normally distributed variables and as equivalent median, 15th, and 85th percentiles for skewed distribution. Categorical variables are summarized as frequency and percentage. Survival estimates are accompanied by $68 \%$ confidence limits equivalent to \pm 1 standard error.

\section{RESULTS}

\section{Submucosal Cancer Characteristics and Surgery}

As submucosal invasion increased, cancer length $(P<.001)$, cancer width $(P<.001)$, cancer area $(P<$ $.001)$, histologic grade $(P=.05)$, lymphovascular invasion $(P=.007)$, number of positive nodes $(P<.001)$, and pathologic $\mathrm{N}$ classification $(P<.001)$ increased (Table 2, Figure 2). Total number of nodes sampled increased $(P=.02)$, and more thoracotomies were performed
$(P=.05)$ with increasing depth of invasion (Table 2$)$. Median number of lymph nodes resected was 10 (15th and 85 th percentiles, 3 and 19) for transhiatal esophagectomy and 18 (15th and 85th percentiles, 6 and 32) for thoracotomy. Histopathologic cell type was not associated with cancer characteristics (Table E1).

\section{Risk Factors for Lymph Node Metastases}

Prevalence of lymph node metastases was similar for men and women, age, length of Barrett esophagus, and histopathologic cell type (Table 3). However, cancer dimensions, lymphovascular invasion, and histologic grade were individually associated with greater occurrence of lymph node metastases (Table 4). Owing to the strong association of depth of invasion with cancer characteristics, multivariable analysis identified only invasion of the deep submucosa $(P<.001)$ as an independent risk factor: 45\% (23/ $51)$ of deep cancers versus $10 \%$ (3/29) of middle-third and $7.5 \%(3 / 40)$ of inner-third cancers had lymph node metastases. Lymphovascular invasion was possibly $(P=.06)$ an independent risk factor. Of 26 patients with lymphovascular invasion, 12 (46\%) had lymph node metastases; of 94 without lymphovascular invasion, 17 (18\%) had lymph node metastases $(P=.003)$. Of 5 patients with a $\mathrm{G} 1$ cancer confined to the inner submucosa without lymphovascular invasion, none had lymph node metastases.

\section{Prognostic Factors for Survival}

Survival was $90 \%, 61 \%$, and $46 \%$ at 1,5 , and 10 years after esophagectomy, respectively. For patients with pN0 cancers, survival was $92 \%, 70 \%$, and $53 \%$ at these intervals, but $86 \%, 36 \%$, and $24 \%$ for patients with pN1-2 cancers (Figure 3; $P<.001$ ). No tumor dimension was individually associated with survival because of the overwhelming effect of lymph node metastasis on mortality (Table 5). Multivariable analysis also identified older age at esophagectomy as a risk factor; however, recursive partitioning indicated that lymph node metastasis also overwhelms the effect of age (Figure 4). Thus, 5-year survival was $94 \%$ for younger pN0 patients and $62 \%$ for older ones, but $36 \%$ for $\mathrm{pN} 1-2$ patients regardless of age.

\section{DISCUSSION \\ Principal Findings}

This study demonstrates that submucosal cancer is not a superficial cancer. For submucosal esophageal cancer (pT1b), both deep submucosal invasion and possibly lymphovascular invasion predicted regional lymph node metastases. Only regional lymph node metastasis was associated with mortality.

Lymphatic anatomy. D2-40 immunohistochemical staining differentiates lymphatic endothelium from capillary endothelium, permitting better understanding of the lymphatic anatomy of the esophageal wall. ${ }^{2,3}$ Lymphatics are 
TABLE 2. Cancer characteristics by depth of invasion

\begin{tabular}{|c|c|c|c|c|}
\hline & Inner $(n=40)$ & Middle $(\mathbf{n}=\mathbf{2 9})$ & Deep $(n=51)$ & \\
\hline Variable/response & $\begin{array}{l}\text { No. }(\%) \text { or } 15 \text { th } / 50 \text { th } / 85 \text { th } \\
\text { percentiles }\end{array}$ & $\begin{array}{c}\text { No. }(\%) \text { or } 15 \text { th } / 50 \text { th } / 85 \text { th } \\
\text { percentiles }\end{array}$ & $\begin{array}{c}\text { No. }(\%) \text { or } 15 \text { th } / 50 \text { th } / 85 \text { th } \\
\text { percentiles }\end{array}$ & $\boldsymbol{P}$ \\
\hline Greatest cancer length $(\mathrm{cm})^{*}$ & $0 / 1.2 / 2.7$ & $1.0 / 1.9 / 3.0$ & $1.5 / 2.5 / 4.0$ & $<.001$ \\
\hline Greatest cancer width $(\mathrm{cm})^{*}$ & $0 / 0.8 / 1.7$ & $0.5 / 1.1 / 2.0$ & $0.8 / 1.5 / 3.0$ & $<.001$ \\
\hline Cancer area $\left(\mathrm{cm}^{2}\right)^{*}$ & $0 / 1.0 / 4.0$ & $0.2 / 2.2 / 4.0$ & $1.1 / 3.4 / 12$ & $<.001$ \\
\hline Histopathologic type & & & & .7 \\
\hline Adenocarcinoma & $35(88)$ & $26(90)$ & $46(90)$ & \\
\hline Squamous cell carcinoma & $5(12)$ & $3(10)$ & $5(9.8)$ & \\
\hline Histologic grade & & & & .05 \\
\hline G1 & $5(12)$ & $4(14)$ & $7(14)$ & \\
\hline $\mathrm{G} 2$ & $24(60)$ & $16(55)$ & $17(33)$ & \\
\hline G3 & $11(28)$ & $9(31)$ & $27(53)$ & \\
\hline Lymphovascular invasion & $4(10)$ & $5(17)$ & $17(33)$ & .007 \\
\hline No. of positive lymph nodes & & & & $<.001$ \\
\hline 0 & $37(92)$ & $26(90)$ & $28(55)$ & \\
\hline 1 & $3(7.5)$ & $1(3.4)$ & $16(31)$ & \\
\hline 2 & $0(0)$ & $0(0)$ & $4(7.8)$ & \\
\hline 3 & $0(0)$ & $0(0)$ & $2(3.9)$ & \\
\hline 4 & $0(0)$ & $0(0)$ & $1(2.0)$ & \\
\hline$\geq 5$ & $0(0)$ & $2(6.9)$ & $0(0)$ & \\
\hline Pathologic classification & & & & $<.001$ \\
\hline pNO & $37(92)$ & $26(90)$ & $28(55)$ & \\
\hline pN1 & $3(7.5)$ & $1(3.4)$ & $20(39)$ & \\
\hline $\mathrm{pN} 2$ & $0(0)$ & $2(6.9)$ & $3(5.9)$ & \\
\hline Extracapsular lymph node involvement & $0 / 3$ & $0 / 3$ & $5 / 21 \dagger$ & .2 \\
\hline Total number of lymph nodes sampled & $4 / 10 / 22$ & $6 / 16 / 32$ & $5 / 15 / 29$ & .02 \\
\hline Surgical approach: thoracotomy & $20(50)$ & $18(62)$ & $36(71)$ & .05 \\
\hline
\end{tabular}

*Inner, $\mathrm{n}=39$; middle, $\mathrm{n}=28$; deep, $\mathrm{n}=50$. $\dagger$ Data available.

abundant in the lamina propria of the mucosa. These lymphatics have no direct connections with regional lymphatics or thoracic duct, and they drain through the mural lymphatic plexus to reach regional lymph nodes (see Figure 1, A). Lymphatics are more sporadic in the submucosa and muscularis propria. In the submucosa they appear to be concentrated in the deep submucosa and have direct connections to more central lymphatic channels. ${ }^{2}$

Submucosal cancer characteristics. More deeply invading esophageal cancers are larger. ${ }^{8}$ Our study shows that as submucosal cancers invade deeper, they grow centrifugally as well, with cancer surface area tripling as invasion proceeds from superficial to deep submucosa. Deeper submucosal invasion is associated with more undifferentiated cancer growth (more G2 and G3 cancers) for both esophageal $^{4}$ and colorectal cancers. ${ }^{9}$ G1 cancers were uncommon and equally distributed through the submucosa, G2 cancers predominated in the more superficial submucosa, and deep submucosal cancers were most likely to be G3 cancers. It may be that cancers dedifferentiate as they invade; however, another explanation is that more aggressive cancers are more likely to be deeply invasive on presentation. Regardless, grade, a crude measure of cancer biology, is linked with cancer size and invasion.
Regional lymph node metastasis. Reported to be rare in mucosal cancers, ${ }^{10}$ regional lymph node metastasis is surprisingly common in submucosal cancers, and the likelihood of this increases exponentially with deeper submucosal invasion. ${ }^{11}$ This conforms with recent immunohistochemical mapping of the esophageal lymphatics and characteristics of submucosal cancers. ${ }^{2,3} \mathrm{We}$ and many others ${ }^{3,12-17}$ have found that lymphovascular invasion is the initial step toward regional lymph node metastasis. Similar to our findings, deeper submucosal invasion also has been found to be associated with increasing regional lymph node metastases. ${ }^{12,14,18-22}$

As a cancer grows centrifugally, it encounters more mucosal lymphatics, increasing the possibility of lymphatic invasion and metastases to regional lymph nodes. In addition, with deeper submucosal invasion there is increased likelihood for invasion of lymphatics with more direct connections to regional lymph nodes. Therefore, the growth pattern, both centrifugal and deep, coupled with the unique lymphatic anatomy of the esophagus, produces a watershed in the deep submucosa, the invasion of which results in a high risk of regional lymph metastases. Nearly one half of patients with invasion of the deep submucosa have regional lymph node metastases. 

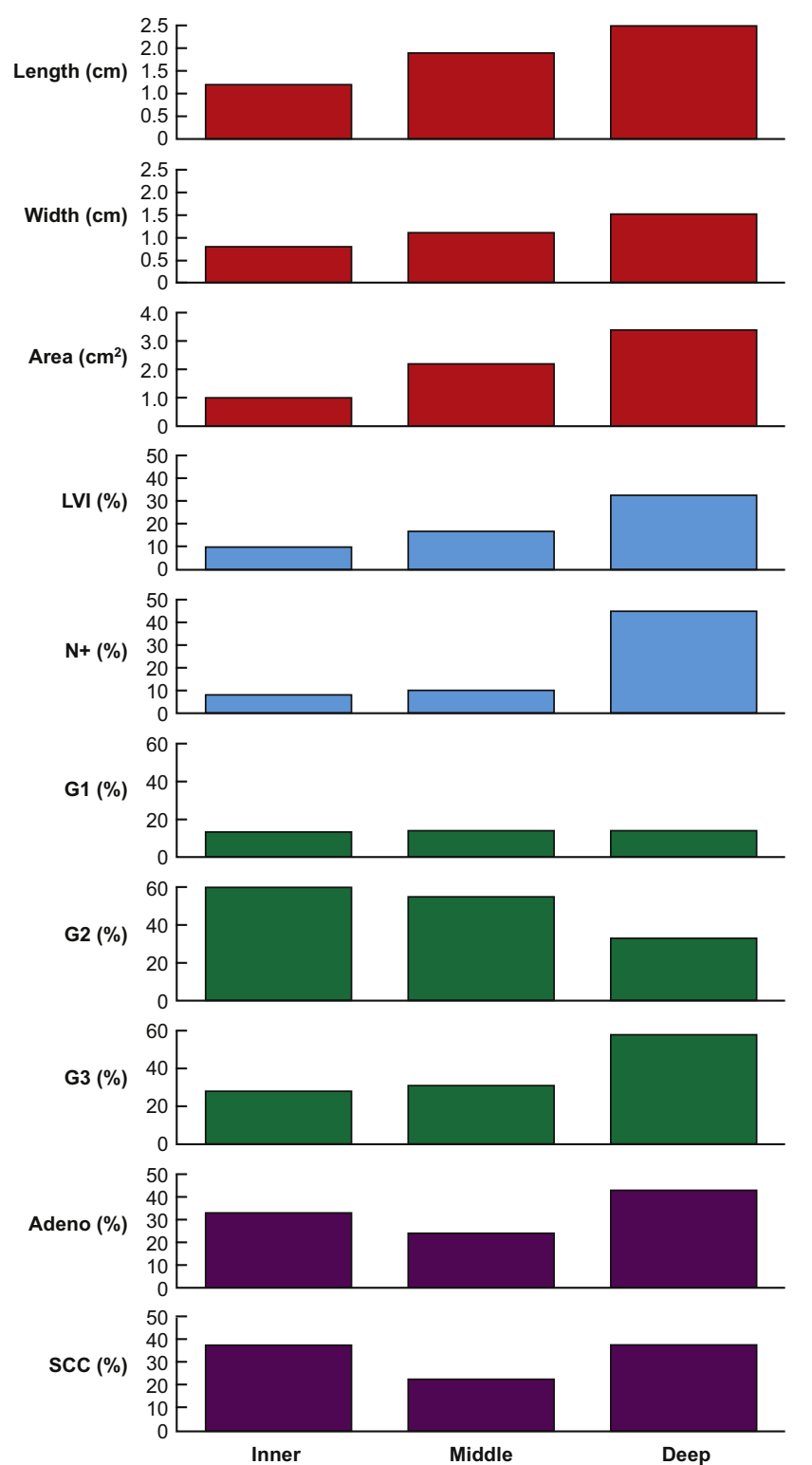

FIGURE 2. Histograms demonstrating relationship of cancer characteristics to depth of submucosal cancer invasion. Adeno, adenocarcinoma; LVI, lymphovascular invasion; $S C C$, squamous cell carcinoma.

Multiple regional lymph node metastases are also associated with deeper submucosal invasion. We found that no patient with superficial invasion had more than 1 regional lymph node metastasis. However, $7 \%$ of cancers with invasion of the middle third and $14 \%$ of deep submucosal cancers had 2 or more regional lymph node metastases. Extracapsular lymph node involvement was observed only with deep submucosal invasion.

Survival. Presence of regional lymph node metastasis has an overwhelming negative effect on survival. Curiously, no other examined variable was prognostic, because of the strong association of cancer characteristics with lymphatic metastases. The association of deep submucosal invasion
TABLE 3. Prevalence of lymph node metastases according to patient and cancer characteristics

\begin{tabular}{|c|c|c|c|}
\hline Characteristic & $\begin{array}{c}\text { No. of } \\
\text { Patients }\end{array}$ & $\begin{array}{c}\text { No. with lymph node } \\
\text { metastases }(\%)\end{array}$ & $P$ \\
\hline \multicolumn{4}{|l|}{ Demographics } \\
\hline Sex & & & .8 \\
\hline Men & 102 & $25(24)$ & \\
\hline Women & 18 & $4(22)$ & \\
\hline Age at operation (y) & & & .7 \\
\hline$\leq 55$ & 31 & $10(32)$ & \\
\hline $56-65$ & 31 & $7(23)$ & \\
\hline $66-71$ & 26 & $3(12)$ & \\
\hline$>71$ & 32 & $9(28)$ & \\
\hline \multicolumn{4}{|l|}{ Cancer characteristics } \\
\hline Barrett length $(\mathrm{cm})$ & & & .4 \\
\hline 0 & 34 & $6(18)$ & \\
\hline $0.5-2.5$ & 24 & 7 (29) & \\
\hline $3-6$ & 32 & $9(28)$ & \\
\hline $7-14$ & 29 & $7(24)$ & \\
\hline Cancer length $(\mathrm{cm})^{*}$ & & & .02 \\
\hline $0.0-0.9$ & 21 & $2(9.5)$ & \\
\hline $1.0-1.9$ & 33 & $6(18)$ & \\
\hline $2.0-2.9$ & 37 & $12(32)$ & \\
\hline $3.0-8.0$ & 26 & $9(35)$ & \\
\hline Cancer width $(\mathrm{cm})$ & & & .01 \\
\hline $0-0.5$ & 29 & $4(14)$ & \\
\hline $0.6-1.0$ & 33 & $7(21)$ & \\
\hline $1.1-1.9$ & 30 & $7(23)$ & \\
\hline $2.0-5.5$ & 25 & $11(44)$ & \\
\hline Cancer area $\left(\mathrm{cm}^{2}\right)$ & & & .02 \\
\hline $0-0.5$ & 29 & $4(14)$ & \\
\hline $0.6-1.9$ & 26 & $5(19)$ & \\
\hline $2.0-4.9$ & 34 & $8(24)$ & \\
\hline $5.0-40$ & 28 & $12(43)$ & \\
\hline pT1b & & & $<.001$ \\
\hline Inner & 40 & $3(7.5)$ & \\
\hline Middle & 29 & $3(10)$ & \\
\hline Deep & 51 & $23(45)$ & \\
\hline Histopathologic cell type & & & .9 \\
\hline Adenocarcinoma & 107 & $26(24)$ & \\
\hline Squamous cell carcinoma & 13 & $3(23)$ & \\
\hline Histologic grade & & & .09 \\
\hline G1 & 16 & $1(6.2)$ & \\
\hline G2 & 57 & $14(25)$ & \\
\hline G3 & 47 & $14(30)$ & \\
\hline Lymphovascular invasion & & & .004 \\
\hline Yes & 26 & $12(46)$ & \\
\hline No & 94 & $17(18)$ & \\
\hline Esophagectomy & & & .01 \\
\hline Transhiatal & 46 & $5(11)$ & \\
\hline Thoracotomy & 74 & $24(32)$ & \\
\hline
\end{tabular}

$*_{\mathrm{n}}=117$.

with regional nodal metastasis and its effect on survival emphasizes how this lymphatic watershed affects survival.

Increasing patient age was the only other factor associated with increased mortality. Although older patients die sooner than younger patients, the present analysis 
TABLE 4. Risk factors for lymph node metastasis: Logistic regression analysis

\begin{tabular}{|c|c|c|c|c|}
\hline Characteristic & $\begin{array}{l}\text { Odds } \\
\text { ratio* }\end{array}$ & $68 \% \mathrm{CI}$ & $P$ & $\begin{array}{c}\text { Reliability } \\
(\%) \dagger\end{array}$ \\
\hline \multicolumn{5}{|l|}{ Demographics } \\
\hline Male/female & 1.14 & $0.62-2.09$ & .8 & 2.2 \\
\hline \multicolumn{5}{|l|}{ Age at operation (y) } \\
\hline Per 10-y increase & 0.91 & $0.74-1.13$ & .7 & 6.2 \\
\hline \multicolumn{5}{|l|}{ Cancer characteristics } \\
\hline \multicolumn{5}{|l|}{ Barrett length $\ddagger$} \\
\hline Per 1-cm increase & 1.04 & $0.99-1.10$ & .4 & 9.4 \\
\hline \multicolumn{5}{|l|}{ Cancer dimensions } \\
\hline \multicolumn{5}{|l|}{ Length $(\mathrm{cm}) \S$} \\
\hline Per 1-cm increase & 1.42 & $1.23-1.63$ & .02 & 8.5 \\
\hline \multicolumn{5}{|l|}{ Width $(\mathrm{cm}) \S$} \\
\hline Per 1-cm increase & 1.68 & $1.37-2.04$ & .01 & 9.9 \\
\hline \multicolumn{5}{|l|}{ Area $\left(\mathrm{cm}^{2}\right) \S$} \\
\hline Per $1-\mathrm{cm}^{2}$ increase & 1.09 & $1.05-1.13$ & .02 & 6.9 \\
\hline \multicolumn{5}{|l|}{ pT1b width } \\
\hline Middle/inner & 1.42 & $0.61-3.33$ & .7 & 1.9 \\
\hline Deep/inner & 10.13 & $5.24-19.59$ & .001 & 94 \\
\hline \multicolumn{5}{|l|}{ Histopathologic cell type } \\
\hline $\begin{array}{l}\text { Adenocarcinoma/ } \\
\text { squamous cell } \\
\text { carcinoma }\end{array}$ & 1.07 & $0.54-2.14$ & .9 & 0.7 \\
\hline \multicolumn{5}{|l|}{ Histologic grade } \\
\hline G2/G1 & 4.88 & $1.67-14.26$ & .14 & 17 \\
\hline G3/G1 & 6.36 & $2.17-18.64$ & .09 & 1.7 \\
\hline G3/G1-2 & 1.64 & $1.07-2.52$ & .2 & 1.7 \\
\hline $\mathrm{G} 2-3 / \mathrm{G} 1$ & 5.53 & $1.93-15.80$ & .11 & 13 \\
\hline \multicolumn{5}{|l|}{ Lymphovascular invasion } \\
\hline Yes/no & 3.88 & $2.42-6.23$ & .004 & 35 \\
\hline
\end{tabular}

demonstrates reduced survival, corrected for age, in the elderly with submucosal cancers. In these cancers with expected good survival, compared with the average

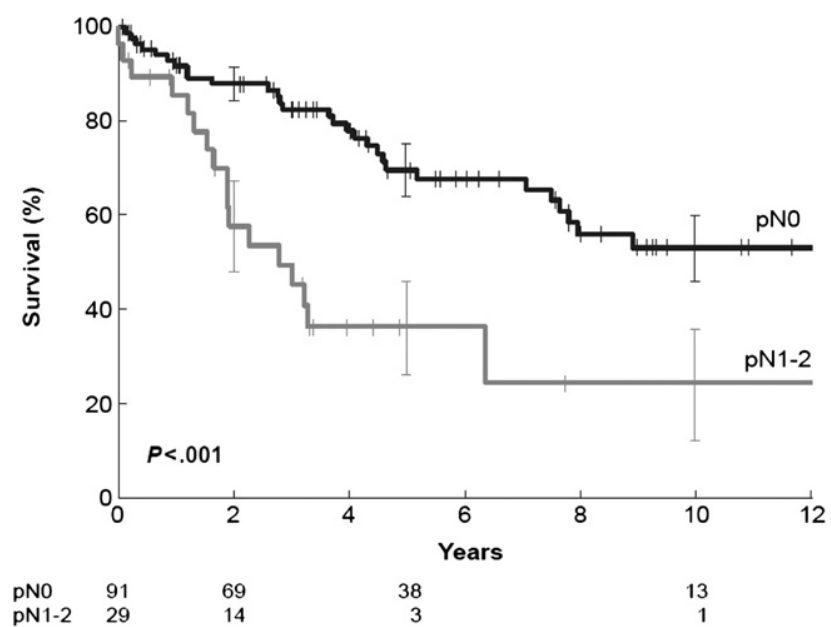

FIGURE 3. Survival after esophagectomy by $\mathrm{pN}$ classification. Vertical bars represent \pm 1 standard error, and legend shows number of patients at risk. Tick marks indicate censored patients.
TABLE 5. Association of individual variables with mortality by Cox proportional hazards analysis

\begin{tabular}{|c|c|c|c|c|}
\hline Characteristic & $\begin{array}{c}\text { Hazard } \\
\text { ratio* }\end{array}$ & $68 \% \mathrm{CI}$ & $P$ & $\begin{array}{c}\text { Reliability } \\
(\%) \dagger\end{array}$ \\
\hline \multicolumn{5}{|l|}{ Demographics } \\
\hline Male/female & 1.28 & $0.85-1.92$ & .6 & 16 \\
\hline \multicolumn{5}{|l|}{ Age at operation $(\mathrm{y})$} \\
\hline Per 10 -y increase & 1.38 & $1.19-1.61$ & .03 & 48 \\
\hline \multicolumn{5}{|l|}{ Cancer characteristics } \\
\hline \multicolumn{5}{|l|}{ Barrett length $\ddagger$} \\
\hline Per $1-\mathrm{cm}$ increase & 0.98 & $0.95-1.02$ & .7 & 4.9 \\
\hline \multicolumn{5}{|l|}{ Cancer dimensions } \\
\hline \multicolumn{5}{|l|}{ Length $(\mathrm{cm}) \S$} \\
\hline Per 1-cm increase & 0.98 & $0.90-1.08$ & .8 & 9.2 \\
\hline \multicolumn{5}{|l|}{ Width $(\mathrm{cm}) \S$} \\
\hline Per 1-cm increase & 1.01 & $0.89-1.16$ & .9 & 8.8 \\
\hline \multicolumn{5}{|l|}{ Area $\left(\mathrm{cm}^{2}\right) \S$} \\
\hline Per $1-\mathrm{cm}^{2}$ increase & 1.00 & $0.98-1.02$ & .9 & 6.7 \\
\hline \multicolumn{5}{|l|}{ pT1b } \\
\hline Middle/inner & 1.04 & $0.71-1.51$ & .9 & 12 \\
\hline Deep/inner & 1.33 & $0.96-1.84$ & .4 & 12 \\
\hline \multicolumn{5}{|l|}{ Histopathologic cell type } \\
\hline $\begin{array}{l}\text { Adenocarcinoma/ } \\
\text { squamous cell } \\
\text { carcinoma }\end{array}$ & 0.65 & $0.45-0.94$ & .2 & 28 \\
\hline \multicolumn{5}{|l|}{ Histologic grade } \\
\hline $\mathrm{G} 2 / \mathrm{G} 1$ & 1.20 & $0.73-1.97$ & .7 & 6.0 \\
\hline $\mathrm{G} 3 / \mathrm{G} 1$ & 1.72 & $1.05-2.81$ & .3 & 7.4 \\
\hline G3/G1-2 & 1.49 & $1.12-1.97$ & .16 & 7.4 \\
\hline $\mathrm{G} 2-3 / \mathrm{G} 1$ & 1.43 & $0.89-2.29$ & .4 & 2.2 \\
\hline \multicolumn{5}{|l|}{ Lymphovascular invasion } \\
\hline Yes/No & 1.38 & $0.95-2.01$ & .4 & 19 \\
\hline \multicolumn{5}{|l|}{$\mathrm{pN}$} \\
\hline $\mathrm{pN} 1 / \mathrm{pN} 0$ & 2.94 & $2.12-4.07$ & .001 & 88 \\
\hline $\mathrm{pN} 2 / \mathrm{pN} 0$ & 3.56 & $1.92-6.60$ & .04 & 69 \\
\hline
\end{tabular}

$\mathrm{CI}$, Confidence interval. *Hazard ratio for univariable analyses. $\dagger$ Percent of times factor appeared in 1000 bootstrapped multivariable models. $\ddagger \mathrm{n}=119 . \S \mathrm{n}=117$.

esophageal cancer, the presence of submucosal invasion, particularly limited to the inner and middle thirds, does not cause overwhelming mortality, and the influence of age on survival can be appreciated.

\section{STRENGTHS AND LIMITATIONS}

This is a single-institution experience covering more than 20 years. It represents a highly selected referral population. It is a surgical series; therefore, patients with submucosal cancers that are not medically operable and those with distant metastases (none of whom we are aware) are not represented. This series may underestimate regional lymph node metastases. ${ }^{23}$ Failure to identify regional lymph node metastases may be a reflection of extent of lymphadenectomy, which increased with time, influenced by change in surgical approach to thoracotomy.

Submucosal cancers are uncommon, but this is a large patient volume of long-term data necessary to provide 


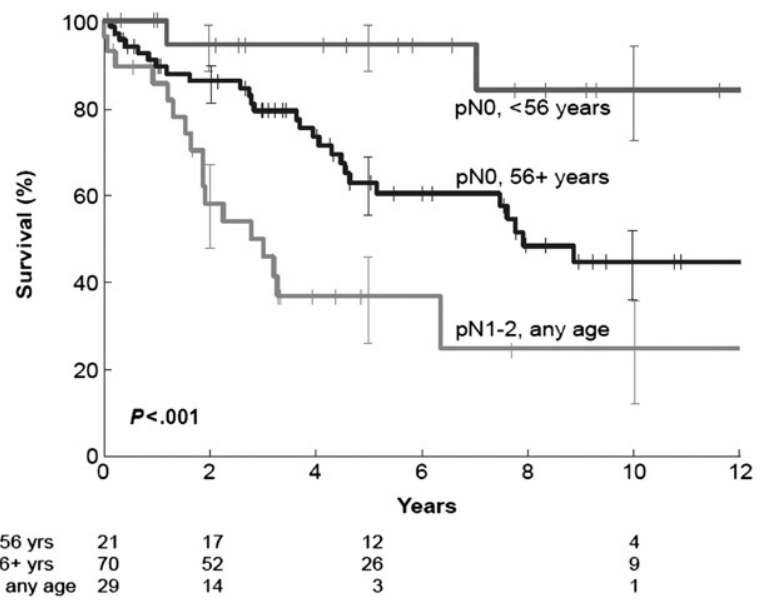

FIGURE 4. Survival after esophagectomy by age and $\mathrm{pN}$ classification. Depiction is as in Figure 3.

strength to identify associations. Although large compared with other reports, it still may be too small to detect weaker associations.

\section{CONCLUSIONS AND RECOMMENDATIONS}

The submucosa is the critical anatomic layer of the esophagus within which there are major lymphatic connections. Cancers invading the submucosa have unique growth features. The interplay of these produces the watershed effect of deep submucosal invasion. Increasing depth of submucosal invasion is associated with a disproportionately increasing occurrence of regional lymph node metastases, leading to decreasing survival.

The potential difficulty in accurately and repeatedly determining depth of submucosal invasion clinically, the high likelihood of regional lymph node metastases for any submucosal cancer (range, 10\%-50\%), and the rarity of a well-differentiated (G1) inner submucosal cancer without lymphovascular invasion requires complete removal of a submucosal esophageal cancer with its regional lymph nodes. Aggressive therapy of more superficial cancers is critical before submucosal invasion occurs.

Because the submucosa lymphatic anatomy is nonhomogeneous, the boundary for a superficial cancer is not at the border of the submucosa and muscularis propria. A submucosal cancer is not a superficial cancer. This term should be limited to mucosal cancer.

We thank Janet Rice for assistance with manuscript preparation and Tess Parry for editorial help.

\section{References}

1. Grotenhuis BA, van Heijl M, Zehetner J, Moons J, Wijnhoven BP, van Berge Henegouwen MI, et al. Surgical management of submucosal esophageal cancer: extended or regional lymphadenectomy? Ann Surg. 2010;252:823-30.

2. Yajin S, Murakami G, Takeuchi H, Hasegawa T, Kitano H. The normal configuration and interindividual differences in intramural lymphatic vessels of the esophagus. J Thorac Cardiovasc Surg. 2009;137:1406-14.
3. Tomita N, Matsumoto T, Hayashi T, Arakawa A, Sonoue H, Kajiyama Y, et al. Lymphatic invasion according to D2-40 immunostaining is a strong predictor of nodal metastasis in superficial squamous cell carcinoma of the esophagus: algorithm for risk of nodal metastasis based on lymphatic invasion. Pathol Int. 2008;58:282-7.

4. Buskens CJ, Westerterp M, Lagarde SM, Bergman JJ, ten Kate FJ, van Lanschot JJ. Prediction of appropriateness of local endoscopic treatment for high-grade dysplasia and early adenocarcinoma by EUS and histopathologic features. Gastrointest Endosc. 2004;60:703-10.

5. Edge SB, Byrd DR, Compton CC, Fritz AG, Greene FL, Trotti A, eds. AJCC cancer staging manual. 7th ed. New York: Springer-Verlag; 2010.

6. Breiman L. Bagging predictors. Machine Learning. 1996;24:123-40.

7. Zhang H, Singer B. Recursive partitioning analysis in the health sciences. New York: Springer-Verlag; 1999.

8. Kim DU, Lee JH, Min BH, Shim SG, Chang DK, Kim YH, et al. Risk factors of lymph node metastasis in T1 esophageal squamous cell carcinoma. J Gastroenterol Hepatol. 2008;23:619-25.

9. Beppu K, Nagahara A, Terai T, Matsumoto K, Shibuya T, Sakamoto N, et al. Clinicopathological characteristics of colorectal cancer less than $10 \mathrm{~mm}$ in diameter and invading submucosa and below. J Gastroenterol Hepatol. 2010; 25(Suppl. 1):S57-61.

10. Kaneshiro D, Rybicki L, Rice TW, Goldblum JR. Clinical significance of the duplicated muscularis mucosae in Barrett esophagus-related superficial adenocarcinoma. Am J Surg Pathol. 2011;35:697-700.

11. Gockel I, Sgourakis G, Lyros O, Polotzek U, Schimanski CC, Lang H, et al. Risk of lymph node metastasis in submucosal esophageal cancer: a review of surgically resected patients. Expert Rev Gastroenterol Hepatol. 2011;5:371-84.

12. Shimada H, Nabeya Y, Matsubara H, Okazumi S, Shiratori T, Shimizu T, et al Prediction of lymph node status in patients with superficial esophageal carcinoma: analysis of 160 surgically resected cancers. Am J Surg. 2006;191:250-4.

13. Barbour AP, Jones M, Brown I, Gotley DC, Martin I, Thomas J, et al. Risk stratification for early esophageal adenocarcinoma: analysis of lymphatic spread and prognostic factors. Ann Surg Oncol. 2010;17:2494-502.

14. Ancona E, Rampado S, Cassaro M, Battaglia G, Ruol A, Castoro C, et al. Prediction of lymph node status in superficial esophageal carcinoma. Ann Surg Oncol. 2008; 15:3278-88.

15. Bolton WD, Hofstetter WL, Francis AM, Correa AM, Ajani JA, Bhutani MS, et al. Impact of tumor length on long-term survival of pT1 esophageal adenocarcinoma. J Thorac Cardiovasc Surg. 2009;138:831-6.

16. Sepesi B, Watson TJ, Zhou D, Polomsky M, Litle VR, Jones CE, et al. Are endoscopic therapies appropriate for superficial submucosal esophageal adenocarcinoma? An analysis of esophagectomy specimens. J Am Coll Surg. 2010;210: 418-27.

17. Eguchi T, Nakanishi Y, Shimoda T, Iwasaki M, Igaki H, Tachimori Y, et al. Histopathological criteria for additional treatment after endoscopic mucosal resection for esophageal cancer: analysis of 464 surgically resected cases. Mod Pathol. 2006;19:475-80.

18. Bollschweiler E, Baldus SE, Schroder W, Prenzel K, Gutschow C, Schneider PM, et al. High rate of lymph-node metastasis in submucosal esophageal squamouscell carcinomas and adenocarcinomas. Endoscopy. 2006;38:149-56.

19. Westerterp M, Koppert LB, Buskens CJ, Tilanus HW, ten Kate FJ, Bergman JJ, et al. Outcome of surgical treatment for early adenocarcinoma of the esophagus or gastro-esophageal junction. Virchows Arch. 2005;446:497-504.

20. Araki K, Ohno S, Egashira A, Saeki H, Kawaguchi H, Sugimachi K. Pathologic features of superficial esophageal squamous cell carcinoma with lymph node and distal metastasis. Cancer. 2002;94:570-5.

21. Kodama M, Kakegawa T. Treatment of superficial cancer of the esophagus: a summary of responses to a questionnaire on superficial cancer of the esophagus in Japan. Surgery. 1998;123:432-9.

22. Endo M, Yoshino K, Kawano T, Nagai K, Inoue H. Clinicopathologic analysis of lymph node metastasis in surgically resected superficial cancer of the thoracic esophagus. Dis Esophagus. 2000;13:125-9.

23. Rizk NP, Ishwaran H, Rice TW, Chen LQ, Schipper PH, Kesler KA, et al. Optimum lymphadenectomy for esophageal cancer. Ann Surg. 2010;251:46-50.

\section{APPENDIX 1. VARIABLES ASSESSED IN DATA ANALYSES}

Demographics: Sex, age.

Cancer characteristics: Barrett length, cancer dimensions (length, width, area, volume), histopathologic cell type, 
histologic grade, lymphovascular invasion, number of positive lymph nodes, pathologic N-classification, depth of cancer invasion.

\section{Discussion}

Dr David R. Jones (Charlottesville, Va). I thank the Association for the opportunity to discuss this fine paper. I have no disclosures related to the discussion. It is a pleasure to review and then discuss yet another paper from Dr Raja and colleagues from the Cleveland Clinic Foundation. As we are all aware, the Cleveland Clinic and, in particular, the senior author of this paper, Dr Rice, have been leaders in the surgical treatment of esophageal cancer, and this presentation certainly adds value to our understanding of the pathobiology of the disease. Dr Raja, I have 3 questions for you, and I will ask them 1 at a time.

First, given that the submucosal layer is measured to be roughly half a millimeter, how difficult is it in measuring the width and subsequent depth of mucosal invasion by the pathologists? It strikes me that this may be quite subjective. What are your comments with respect to this issue?

Dr Raja. Our pathologists tell us the submucosa varies from 200 to $1000 \mu \mathrm{m}$. Although there is a degree of subjectivity, dividing it into thirds has not been a problem for our and other pathologists. Submucosal cancers have a defined prevalence of regional lymph node metastases, and even invasion of the inner third of the submucosa is associated with meaningful lymphatic metastases.

Dr Jones. Second, how does the information that you have presented affect your clinical decision making when your initial endoscopic ultrasound report classifies the $\mathrm{T}$ stage as $\mathrm{T} 1 \mathrm{a}$ or $\mathrm{T} 1 \mathrm{~b}$ ? Would you now advocate a transthoracic approach and perhaps a more aggressive mediastinal node dissection versus, for instance, a transhiatal?

Dr Raja. We rely on endoscopic ultrasound to identify submucosal (T1b) cancer. In patients in whom the clinical differentiation of intramucosal from submucosal cancer is uncertain, we use endoscopic mucosal resection and pathologic review of that specimen. We believe that endoscopic therapies should be reserved for no more than intramucosal cancer.

We have previously published that a minimum of 10 lymph nodes need to be resected and examined to maximize 5-year survival in patients with $\mathrm{T} 1$ cancer.* This frequently requires a transthoracic approach. This study has taught us that long, circumferential, poorly differentiated cancers and those cancers with lymphovascular invasion are more likely to have deep submucosal invasion and thus a very high rate of regional lymph node metastases. Today these findings would dictate a transthoracic approach. In our study, $60 \%$ of patients had a transthoracic approach and $40 \%$ had a transhiatal approach, and there was no survival difference.

Dr Jones. Thank you. You actually addressed my last question with how this relates to endoscopic mucosal resection.

\footnotetext{
* Rizk N, Venkatraman E, Park B, Flores R, Bains MS, Rusch V; American Joint Committee on Cancer staging system. The prognostic importance of the number of involved lymph nodes in esophageal cancer: implications for revisions of the American Joint Committee on Cancer staging system. J Thorac Cardiovasc Surg. 2006;132:1374-81.
}

Dr Hiran Fernando (Boston, Mass). Dr Raja, that was an excellent presentation. You showed a couple of slides that correlated depth of invasion with grade and with length and with the area of the tumor that you see. Those would be much easier end points to measure preoperatively if you were contemplating doing a submucosal resection or an endoscopic resection for these patients. Do you know what the outcomes are for those 3 things - the grade, the length, and the area-related to things such as survival and incidence of occult nodal disease?

Dr Raja. By univariable analysis, all of these factors were found to be significant for regional lymph node metastases. Because of the interplay among these factors, multivariable analysis identified only one important predictor of regional lymph node metastases: deep submucosal invasion. Subsequent survival was related to the presence of regional lymph node metastases. Although one could use these other factors that were significant in univariable analysis, the most reliable factor for clinical decision making is deep submucosal invasion.

Dr Wayne L. Hofstetter (Houston, Tex). I congratulate you on a nice presentation. I have a couple of questions. You mentioned that the D2-40 marker was used. Did you go back retrospectively and look for submucosal invasion with the D2-40 marker or immunohistochemistry or, secondarily, on the older specimens, did you rereview for lymphovascular invasion?

Dr Raja. We did not use the D2-40 marker. Our pathologists reviewed all hematoxylin and eosin slides for lymphovascular invasion.

Dr Hofstetter. When we rereviewed our slides with a second pathologist, we found that we upstaged to lymphovascular invasion about $10 \%$ of the time, so that was interesting to us.

The second question was regarding patients that manifested superficial submucosal invasion. You had $8 \%$ that were lymph node positive. How many of those patients were lymphovascular invasion positive or lymphovascular invasion negative? This information has implications in terms of the applicability of endoscopic mucosal resection.

Dr Raja. Forty-six percent of patients with lymphovascular invasion had regional lymph node metastases as opposed to $18 \%$ without regional lymph node metastases. For patients with only inner submucosal invasion, lymphovascular invasion was present in none with lymph node metastasis and $11 \%$ without lymph node metastasis, a reflection of $8 \%$ prevalence of regional lymph node metastasis.

Dr Hofstetter. Finally, in terms of the patients that were T1b, $\mathrm{N} 1$, you revealed that overall survival was $36 \%$ at 5 years. I am not surprised that there was no difference in your approach surgically from transthoracic to transhiatal, because this is a marker, as you are indicating, of watershed or systemic disease. Because we are having such poor outcomes with these T1b, N1 patients, are you considering neoadjuvant therapy for this group of patients if they could be identified preoperatively?

Dr Raja. When regional lymph node metastasis is found at resection, we offer our patients postoperative adjuvant therapy. Preoperatively, if regional lymph node metastasis is detected in patients with submucosal cancer, neoadjuvant therapy is prescribed. For the majority of patients with submucosal cancer, neoadjuvant therapy is excessive. 
Dr Toni Lerut (Leuven, Belgium). Dr Raja, thank you very much and congratulations for an original study. We have done a similar study on a similar number of patients. We found a much higher incidence of positive lymph nodes in the more superficial layer, as well as in the deeper layers, than displayed by the data that you showed. This was true particularly in squamous but also in adenocarcinoma, up to $33 \%$ positive nodes for the superficial layer. You said that you had $40 \%$ transhiatal esophagectomies and $60 \%$ transthoracic esophagectomies. I suspect that you have done proportionally more transhiatal resections for the more superficial carcinomas that also happened to be smaller carcinomas. We all know that the more nodes you remove, the greater the chance for positive nodes. Could you give us more insight in that respect? What was the number of removed nodes?

Dr Raja. The median number of lymph nodes resected was 14 (10 with the transhiatal approach and 18 with the transthoracic approach). A transthoracic approach was used in $50 \%$ of patients with inner cancers, $62 \%$ with middle cancers, and $71 \%$ with deep cancers. Eleven percent had squamous cell cancer, too few to analyze. Your supposition that transhiatal resection was used less frequently for cancer with deeper invasion is correct. Therefore, it is possible that resecting more regional lymph nodes for less invasive cancer may reveal a higher prevalence of lymph node metastases in this group.

Dr Lerut. We in fact had 30 as a mean.

My second question relates to the survival curves. You showed that older age is doing worse, but that is probably because this is a curve showing the overall survival. Wouldn't it be better to show disease-free survival, which is a more cancer-specific survival curve?

Dr Raja. Cancer-specific mortality is a soft end point, and cancer recurrence is similarly problematic. For these reasons, we use all-cause mortality.

Dr Sebastien Gilbert (Ottawa, Ontario, Canada). Thank you for your excellent presentation. I would like to know whether endoscopic mucosal resection is routine in your evaluation of these patients inasmuch as endoscopic ultrasound alone, even with the highest resolution probe, has difficulty distinguishing between mucosal and submucosal lesions. Second, in the case of intramucosal esophageal cancer arising in the background of dysplastic Barrett esophagus, is there an acceptable threshold in the probability of lymph node metastases below which you may consider endoscopic resection and ablation with close follow-up, and beyond which you would recommend esophageal resection?

Dr Raja. We do not routinely use endomucosal resection in patients with submucosal cancer. Endomucosal resection is used to differentiate between deep intramucosal and superficial submucosal invasion. Because of the unacceptable prevalence of regional lymph node metastases in any patient with submucosal cancer, we recommend that they undergo an esophagectomy.

Dr Stephen Cassivi (Rochester, Minn). I will make 2 points. One is to congratulate your group again for parsing out the esophageal wall in a way that we have not seen before. You have taken an area that is 500 to $1000 \mu \mathrm{m}$ in depth and given us a lot of information.

Second, I would like to emphasize, and maybe you can confirm this, that there is $10 \%$ lymphovascular invasion in just the superficial part of the submucosa and an $8 \%$ lymph node metastases. The true divide, from a therapeutic standpoint, is therefore at the muscularis mucosa. In terms of minimally invasive or endoscopic treatments versus a surgical treatment, I think that lymph node metastases rate is too high to allow for adequate treatment from an endoscopic standpoint. Would you agree?

Dr Raja. Undeniably, submucosal cancers have an exponentially increasing prevalence of regional lymph node metastases with increasing depth of invasion. Alarmingly, $8 \%$ of inner submucosal cancers have regional lymph node metastasis. We agree that the muscularis mucosa is an important divide for therapy. 
TABLE E1. Cancer characteristics by pathologic diagnosis and depth of invasion

\begin{tabular}{|c|c|c|c|c|c|c|c|c|}
\hline \multirow[b]{2}{*}{ Variable/response } & \multicolumn{4}{|c|}{ Adenocarcinoma* } & \multicolumn{4}{|c|}{ Squamous cell carcinoma* } \\
\hline & Inner $(\mathbf{n}=\mathbf{3 5})$ & Middle $(n=26)$ & Deep $(n=46)$ & $\boldsymbol{P}$ & Inner $(\mathbf{n}=\mathbf{5})$ & $\operatorname{Middle} \dagger(\mathbf{n}=\mathbf{3})$ & $\operatorname{Deep}(\mathbf{n}=5)$ & $\boldsymbol{P}$ \\
\hline Greatest cancer length $(\mathrm{cm}) \ddagger$ & $0 / 1.0 / 2.5$ & $0.6 / 1.8 / 3.2$ & $1.4 / 2.5 / 4.0$ & $<.001$ & $1.2 / 2.0 / 4.5$ & $1.0,2.0,2.8$ & $1.8 / 2.2 / 5.5$ & .8 \\
\hline Greatest cancer width $(\mathrm{cm}) \ddagger$ & $0.5 / 1.3$ & $0.1 / 1.3 / 2.0$ & $0.7 / 1.5 / 3.0$ & $<.001$ & $0.5 / 1.0 / 2.7$ & $0.5,1.0,1.0$ & $1.0 / 1.6 / 4.0$ & .2 \\
\hline Cancer area $\left(\mathrm{cm}^{2}\right) \ddagger$ & $0 / 0.4 / 2.5$ & $0 / 2.2 / 6.0$ & $1.0 / 3.2 / 12$ & $<.001$ & $1.2 / 1.4 / 12$ & $0.5,2.0,2.8$ & $1.8 / 3.5 / 22$ & .2 \\
\hline Histologic grade & & & & .2 & & & & .02 \\
\hline G1 & $3(8.6)$ & $4(15)$ & $7(15)$ & & $2(40)$ & $0(0)$ & $0(0)$ & \\
\hline G2 & $21(60)$ & $14(54)$ & $15(33)$ & & $3(60)$ & $2(67)$ & $2(40)$ & \\
\hline G3 & $11(31)$ & $8(31)$ & $24(52)$ & & $0(0)$ & $1(33)$ & $3(60)$ & \\
\hline Lymphovascular invasion & $2(5.7)$ & $5(19)$ & $15(33)$ & .003 & $2(40)$ & $0(0)$ & $2(40)$ & 1.0 \\
\hline No. of positive lymph nodes & & & & $<.001$ & & & & .03 \\
\hline 0 & $32(91)$ & $23(88)$ & $26(57)$ & & $5(100)$ & $3(100)$ & $2(40)$ & \\
\hline 1 & $3(8.6)$ & $1(3.8)$ & $14(30)$ & & $0(0)$ & $0(0)$ & $2(40)$ & \\
\hline 2 & $0(0)$ & $0(0)$ & $3(6.5)$ & & $0(0)$ & $0(0)$ & $1(20)$ & \\
\hline 3 & $0(0)$ & $0(0)$ & $2(4.3)$ & & $0(0)$ & $0(0)$ & $0(0)$ & \\
\hline 4 & $0(0)$ & $0(0)$ & $1(2.2)$ & & $0(0)$ & $0(0)$ & $0(0)$ & \\
\hline$\geq 5$ & $0(0)$ & $2(7.7)$ & $0(0)$ & & $0(0)$ & $0(0)$ & $0(0)$ & \\
\hline Pathologic classification & & & & $<.001$ & & & & .03 \\
\hline pNO & $32(41)$ & $23(88)$ & $26(57)$ & & $5(100)$ & $3(100)$ & $2(40)$ & \\
\hline $\mathrm{pN} 1$ & $3(8.6)$ & $1(3.8)$ & $17(37)$ & & $0(0)$ & $0(0)$ & $3(60)$ & \\
\hline $\mathrm{pN} 2$ & $0(0)$ & $2(7.7)$ & $3(6.5)$ & & $0(0)$ & $0(0)$ & $0(0)$ & \\
\hline $\begin{array}{l}\text { Extracapsular lymph node } \\
\text { involvement }\end{array}$ & $0 / 3$ & $0 / 3$ & $4 / 20$ & .3 & - & - & $1 / 1 \S$ & - \\
\hline $\begin{array}{l}\text { Total No. of lymph nodes } \\
\text { sampled }\end{array}$ & $4 / 11 / 21$ & $5 / 18 / 32$ & $5 / 15 / 32$ & .04 & $0 / 8 / 22$ & $6,6,8$ & $5 / 21 / 29$ & .2 \\
\hline $\begin{array}{l}\text { Surgical approach: } \\
\text { thoracotomy }\end{array}$ & $18(51)$ & $15(58)$ & $31(67)$ & .1 & $2(40)$ & $3(100)$ & $5(100)$ & .02 \\
\hline
\end{tabular}

*No. (\%) or 15th/50th/85th percentiles. †Actual values in 3 patients. $\ddagger$ Inner, $n=34$; middle, $n=25 ;$ deep, $n=45$. Data available on 1/1, not all 3. 